10. White, J. W. C., Cook, E. R., Lawrence, J. R. \& Broecker, W. S. Geochim cosmochim. Acta 49, 237-246 (1985)

11. Sternberg, L. S. L. \& Swart, P. K. Ecology 68, 1898-1905 (1987).

12. Dansgaard, W. Tellus 16, 436-468 (1964).

13. Siegenthaler, U. \& Oescheger. H. Nature 285, 314-317 (1980).

14. Climate of the States. Utah (US Weather Bureau, Washington DC, 1960)

15. Caldwell, M. M. in Physiological Ecology of North American Plant Communities (eds Mooney. H. A. \& Chabot, B. F.) 198-212 (Chapman \& Hall, London, 1985).

16. Coleman, M. C., Shepherd, T. J., Durham, J. J., Rouse, J. D. \& Moore, G. R. Analyt. Chem. 54, 993-995 (1988).

17. Craig, H. Science 133, 1833-1834 (1961).

ACKNOWLEDGEMENTS. We thank $C$. Cook and L. Donovan for help with sample collection and analysis and L. Flanagan and H. Griffiths for their comments on the manuscript. This work was supported by the NSF

\section{Plumage coloration is a sexually selected indicator of male quality}

\section{Geoffrey E. Hill}

Museum of Zoology and Department of Biology, University of Michigan, Ann Arbor, Michigan 48109, USA

FEMALE choice of mates based on the expression of characters that correlate with male quality remains a controversial and largely untested idea'. By choosing quality males, females stand to gain resources $^{2}$, genetic benefits for their offspring ${ }^{3-5}$, or both. In the house finch (Carpodacus mexicanus), male plumage coloration is a function of dietary intake of carotenoids ${ }^{6,7}$. Here I present results of field studies that indicate that females prefer to mate with colourful males and that plumage brightness correlates with a male's capactity for parental care and perhaps its genotypic quality. Artificially brightened males paired more quickly and frequently than sham control or lightened males. Among unmanipulated males, plumage coloration was correlated with nest attentiveness and overwinter survival. In addition, there was a positive correlation between the coloration of fathers and sons.

The house finch is a small, sexually dichromatic passerine that is socially monogamous ${ }^{8,9}$. Unlike many passerine species, house finches do not defend territories during the breeding season $^{9,10}$, although both males and females defend mates from rivals. Pairing begins several weeks before the start of nestbuilding and, once paired, house finches form tight associations.
Paired individuals are rarely seen alone until the female begins to incubate, so the pairing status of individuals can be determined unambiguously before nesting. Within populations, males display continuous variation in plumage coloration, ranging from pale yellow to bright red ${ }^{9,11}$. Captive feeding experiments indicate that all male house finches have the same potential to display bright or drab plumage ${ }^{7}$ and that variation in plumage coloration reflects the type and quantity of carotenoids ingested by individuals at the time of their annual moult ${ }^{6,7}$. In laboratory mate-choice experiments with wild-caught house finches, females display a significant preference for the reddest male available?

To determine whether female house finches use male plumage coloration as a criterion for mate choice in the wild and to investigate whether male plumage coloration might be an indicator of male quality, I studied a breeding population of house finches at Ann Arbor, Michigan. Between 10 February and 21 March in 1989 and 1990, I used hair dyes to brighten 40 males and hair lighteners to lighten 40 males. I also assigned 20 males as sham controls by treating them with colour developer which did not alter plumage coloration. There were no significant differences among treatment groups in the size or pre-manipulation plumage scores of males, but all three groups differed significantly in post-manipulation plumage scores (Table 1). The range of plumage scores of manipulated males (96-177) fell within the range of natural plumage coloration in the Ann Arbor population (87-177).

There were no significant differences in dispersal or mortality between manipulated and unmanipulated males $\left(\chi^{2}=0.12\right.$, d.f. $=1, P>0.25)$ or among manipulated males used in different treatments (Table 1). Brightened males were significantly more likely to attain a mate than lightened or sham-control males, and sham-control males were more successful than lightened males (Table 1). Of the males that paired, brightened males paired earlier than lightened or sham-control males (Table 1), but the differences were not significant. Thus, field experiments indicate that female house finches prefer to pair with brightly plumaged males.

Male house finches feed their mates during incubation as well as their offspring ${ }^{8,12}$. To test whether male coloration reflects a male's ability to provide food for its mate and offspring, I recorded the time between feeding visits by males at 32 nests. I found a significant correlation between male attentiveness

TABLE 1 Results of plumage coloration manipulation experiments

\begin{tabular}{|c|c|c|c|c|c|}
\hline Male characteristics & $\begin{array}{c}\text { Brightened }(N=40) \\
\bar{x}(\text { s.d. })\end{array}$ & $\begin{array}{c}\text { Sham control }(N=20) \\
\bar{x}(\text { s.d. })\end{array}$ & $\begin{array}{c}\text { Lightened }(N=40) \\
\bar{x}(\text { s.d. })\end{array}$ & Test statistic & $P$ \\
\hline Weight (g) & $21.9(1.3)$ & $22.3(1.4)$ & $21.8(1.3)$ & $0.87^{*}$ & 0.42 \\
\hline Wing length $(\mathrm{mm})$ & $80.2(1.8)$ & $79.3(1.6)$ & $80.3(2.3)$ & $1.83^{*}$ & 0.17 \\
\hline Original plumage score & $140.7(12.5)$ & $139.9(14.3)$ & $141.0(11.4)$ & $0.05^{*}$ & 0.95 \\
\hline Manipulated plumage score & $161.6(7.9)$ & $139.9(14.3)$ & $129.4(10.3)$ & $98.7^{*}$ & 0.0001 \\
\hline Number resighted (proportion resighted) & $23(0.58)$ & $10(0.50)$ & $26 \quad(0.65)$ & $1.30 \dagger$ & $>0.25$ \\
\hline Number paired (proportion paired) & $22(1.00)$ & $6(0.60)$ & $7 \quad(0.27)$ & $24.75 \dagger$ & 0.0001 \\
\hline Time to pair (days) $\ddagger$ & $12.1(12.5)$ & $20.2(17.8)$ & $27.8(22.4)$ & $2.82^{*}$ & 0.07 \\
\hline
\end{tabular}

Higher plumage scores correspond to brighter plumage; see ref. 9 for details of scoring technique. 1 captured house finches at feeding stations and individually marked them with one aluminium and three coloured plastic leg bands. Males used in the experiment had dye, lightener, or colour developer applied to pigmented regions of their plumage ${ }^{9}$ at times between 13:00 and 15:00 on the day they were trapped. After excess colourant was rinsed from their feathers, males were placed in front of a heat lamp for $2 \mathrm{~h}$ to dry, held overnight with food and water ad lib, and released at 10:00 the next morning. All manipulations were completed before the onset of nestbuilding in the study population. Only previously unbanded males were included in the manipulation. They were assigned to treatment groups so that each group received approximately the same number of males each day and so that males in each treatment were similar in size and pre-manipulation plumage score. Males were counted as 'resighted' if they were seen at least $48 \mathrm{~h}$ after release and 'paired' if they were seen in exclusive association with a female. In 1990, one brightened male was trapped 3 weeks after release but was otherwise not seen, so this male was counted as resighted but was excluded from pairing data. There were no significant differences between years in the pre-manipulation plumage scores or sizes of males or in the effects of the manipulations, so data were pooled for 1989 and 1990.

$* F$, One-way analysis of variance (ANOVA).

$\dagger \chi^{2}$. One-tailed test.

$\ddagger$ Only males that paired were counted in the time to pair comparison, as measured by the interval between release following manipulation and exclusive association with a female. 
TABLE 2 Nest and mate desertion by females

\begin{tabular}{|c|c|c|c|c|c|}
\hline & Successful $(N=78)$ & Failed $(N=60)$ & Abandoned $(N=17)$ & Test statistic & $P$ \\
\hline Number renesting (proportion renesting) & $42 \quad(0.54)$ & $41(0.68)$ & $9 \quad(0.53)$ & $3.28+$ & $>0.10$ \\
\hline Number renesting with same male (proportion) & $42(1.00)$ & $38 \quad(0.93)$ & $1(0.11)^{*}$ & $55.87 \dagger$ & 0.001 \\
\hline Mean plumage score (s.d.) & $152.3(8.9)$ & $152.2(6.5)$ & $144.4(12.3)$ & $6.02 \div$ & 0.003 \\
\hline
\end{tabular}

Success of first nesting attempt by pairs, pooled for 1988-90. Nests were deemed successfut if young fledged, failed if part or all of the nest contents disappeared before fledging and abandoned if a complete, intact clutch or brood was deserted.

* The female from the only pair to renest together after abandoning a nest, abandoned the second nest as well.

$\dagger \chi^{2}$. One-tailed test.

$\ddagger F$, One-way ANOVA.

(mean rate of feeding visits) and male coloration (Fig. 1a), indicating that plumage coloration is a reliable signal of male parental investment. Choosing an inattentive male as a mate seems to impose direct cost on the female. Eleven per cent of females abandoned both their nest and mate before eggs hatched (Table 2); males that were deserted were significantly less
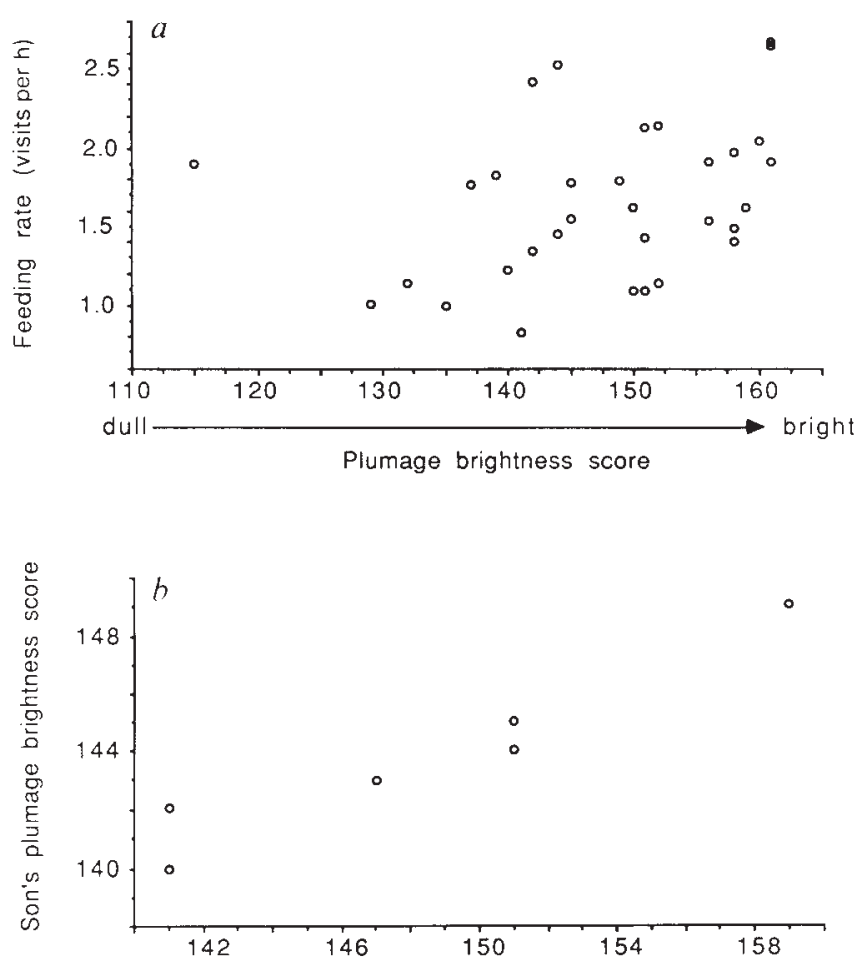

Father's plumage brightness score

FIG. $1 a$, Male nest attentiveness (mean rate of feeding visits) in relation to plumage score $\left(r_{\mathrm{s}}=0.42, n=32, P<0.05\right)$. Feeding rate was measured by observing the interval between visits by the attending male. Two or three feeding intervals, recorded at least $24 \mathrm{~h}$ apart, were obtained for each male and all observations were conducted at times between 06:00 and 13:00 during incubation (between laying of the last egg in a clutch and hatching of the first egg). To test for age effects, I repeated the comparison using only the attendance rates of 13 males known to be two years old or older. Again, there was a significant positive correlation between male plumage score and attentiveness $\left(r_{\mathrm{s}}=0.63, n=13, P<0.05\right)$. $b$, Relationship between the plumage score of fathers and sons $\left(r_{\mathrm{s}}=0.91, n=6, P<0.01\right)$. Sons were banded in a nest for which the attending male's plumage score was known. The plumage score of sons was recorded the following year when they returned to the study site as yearling males. Of the seven sons that returned, two came from the same nest and the remaining five came from different nests attended by different males. To maintain independence of points, a single mean plumage score value for the brothers was used in the analysis. colourful on average than males that were not deserted (Table 2). Females depend on their mates for food during incubation and cases of desertion by females probably result from inadequate provisioning by males.

In addition to resource benefits, females may also gain genetic benefits by choosing to mate with a colourful male. I compared the mean coloration of males banded in 1988 or 1989 and which returned in the following year with the mean coloration of males that did not return. To make the comparison less susceptible to dispersal bias, I also considered only males that paired in 1988 or 1989. In all comparisons, returning males were significantly more colourful than males that did not return (Table 3), suggesting that colourful plumage is an indicator of male viability and perhaps genetic quality ${ }^{13}$, although the relationship between colour and viability may be due to phenotypic effects.

In support of the idea that plumage coloration may be used by females to assess male genotypic quality, is a correlation between the coloration of fathers and sons. According to the good genes models of sexual selection, the overall genotypic quality of a male determines how well it will perform in its environment and the degree to which it will achieve maximum expression of a display trait ${ }^{14-17}$. These models predict a positive correlation between character expression of father and son ${ }^{14-17}$. I compared the plumage scores of seven males that were banded as nestlings and returned the following year to the plumage scores of their fathers and found a significant positive correlation (Fig. 1b). Although this correlation fits predictions of the 'good genes' models, it could also be due to maternal or paternal effects as colourful males tend to provide more food and probably pair with higher quality females than drab males.

These observations indicate that female house finches prefer brightly plumaged males and that, by choosing a colourful male, females gain resources and possibly genetic benefits for offspring. This result provides empirical support for the idea that plumage coloration serves as a signal of male quality ${ }^{4}$ and corroborates previous studies on intersexual selection for integumentary pigmentation in fish ${ }^{18-22}$. Carotenoid pigmenta-

TABLE 3 Male plumage coloration in relation to overwinter survival

\begin{tabular}{llrlcc}
\hline & & \multicolumn{3}{c}{ Plumage score } \\
Interval & \multicolumn{1}{c}{ Status } & $N$ & $\bar{x}($ s.d.) & $t^{*}$ & $P$ \\
$1988-89$ & All returned & 63 & $148.0(9.1)$ & 1.66 & 0.05 \\
& All not returned & 87 & $145.2(10.9)$ & & \\
& Paired returned & 36 & $150.6(7.9)$ & 1.70 & 0.05 \\
& Paired not returned & 32 & $147.3(7.9)$ & & \\
$1989-90$ & All returned & 82 & $149.1(10.8)$ & 2.45 & 0.007 \\
& All not returned & 130 & $144.7(13.7)$ & & \\
& Paired returned & 55 & $152.0(10.1)$ & 1.89 & 0.03 \\
& Paired not returned & 39 & $148.1(9.3)$ & & \\
\hline
\end{tabular}

Males were banded or sighted between 1 February and 1 July in year 1. Males counted as returned were trapped or sighted between 1 February and 1 July in year 2 .

* One-tailed $t$-test comparing mean plumage scores of adjacent rows. 
tion may prove to be a display character that has independently evolved as a viability indicator in a diverse array of taxa.

\section{Received 27 November 1990; accepted 4 February 1991}

1. Bradbury, J. W. \& Andersson, M. B. (eds) Sexual Selection; Testing the Alternatives (Wiley, New York, 1987)

Hoelzer, G. A. Anim. Behav. 38, 1067-1078 (1989).

3. Zahavi, A. J. theor. Biol. 53, 205-214 (1975).

4. Hamilton, W. D. \& Zuk, M. Science 218, 384-387 (1982).

5. Andersson. M. Evolution 40, 804-816 (1986).

5. Andersson. M. Evolution 40, 804-816 (1986),

6. Brush, A. H. \& Power, D. M. Aut
7. Hill, G. E. Auk (in the press).

8. Gill, D. E. \& Lanyon, W. E. Bird-Banding 36, 1-14 (1965)

9. Hill, G. E. Anim. Behav. 40, 563-572 (1990).

10. Thampson, W. L. Condor 62, 245-271 (1960)

11. Michener, H. \& Michener, J. R. Condor 33, 12-19 (1931)

12. Bergtoid, W. H. Auk 30, 40-73 (1913).

13. Crespi, B. J. \& Bookstein. F. L. Evolution 43, 18-29 (1989)

13. Crespi, B. J. \& Bookstein, F. L. Evolution 43, 18-29 (1989)

14. Andersson. M. Biol. J. Linn Soc. 17, 375-393 (1982).

16. Kodric-Brown, A. \& Brown, J. H. Am. Nat. 124, 309-323 (1984)

17. Nur, N. \& Hasson, O. J. theor. Biol. 110, 275-297 (1984).

18. Endler, J. A. Evolution 34, 76-91 (1980)

19. Endler, J. A. Environ biol. Fishes 9, 173-190 (1983)

20. Kodric-Brown, A. Behavl ecol. Sociobiol, 17, 199-205 (1985)

21. Kodric-Brown, A. Behavi ecol. Sociobiol. 25, 393-401 (1989).

22. Milinski, M. \& Bakker, T. C. M. Nature 344, 330-333(1990)

ACKNOWLEDGeMENTS. I thank B. A. Hazlett, W. G. Hoimes, L. D. Ligon, M. C. Mckitrick and R. B. Payne for comments on this manuscript. This research was supported by the American Museum of Natural History, the Animal Behavior Society, Sigma Xi, the American Ornithologists' Union, and the University of Michigan.

\section{The cyclops mutation blocks specification of the floor plate of the zebrafish central nervous system}

\author{
Kohei Hatta, Charles B. Kimmel, Robert K. Ho \\ \& Charline Walker
}

Institute of Neuroscience, University of Oregon, Eugene, Oregon 97403, USA

THE floor plate is a set of epithelial cells present in the ventral midline of the neural tube in vertebrates ${ }^{1}$ that seems to have an important role in the developmental patterning ${ }^{2}$ of central nervous system fibre pathways $\mathbf{s}^{3,4}$, and arrangements of specific neurons ${ }^{5}$. The floor plate arises from dorsal ectodermal cells closely associated with the mesoderm that forms notochord ${ }^{6}$, and it may depend on interactions from the notochord for its specification. To learn the nature of these interactions we have analysed mutations in zebrafish (Brachydanio rerio). We report here that in wild-type embryos the floor plate develops as a simply organized single cell row, but that its development fails in embryos bearing the newly discovered zygotic lethal 'cyclops' mutation, cyc-1(b16). Mosaic analysis establishes that cyc-1 blocks floor plate development autonomously and reveals the presence of homeogenetic induction between floor plate cells.

The floor plate (FP) can be visualized during key stages of embryonic development in the spinal cord by the distinctive cuboidal morphology of its cells, and by labelling with the monoclonal antibody zn-5. It is positioned precisely in the midline just beneath the central canal, and is but a single cell wide (Fig. 1). In contrast, FP structure in most vertebrates is more complex. The antibody zn-5 seems to recognize a cellsurface antigen ${ }^{7}$, whose expression by FP cells is strongest on faces apposed to one another, in contrast to facing their lateral central nervous system (CNS) and ventral (notochord) neighbours. The labelling by zn-5 also indicates that the FP extends through the hindbrain and midbrain ${ }^{7}$, and ends abruptly at the midbrain/forebrain boundary. In the one-day embryo FP cells in the hindbrain are more flattened in the anterior-posterior dimension than are those in the spinal cord, and they contact one another in a staggered linear arrangement rather than in simple end-to-end fashion (Fig. $1 a, d$ ).

Early cells that will form the FPlie dorsally, close to notochord precursors, and single clones founded during blastula stages frequently include both cell types ${ }^{8}$. Cellular intercalations ${ }^{9}$ elongate the two primordia into longitudinal rows, the FP overlying the notochord. Cell transplantation (Fig. 1b,c) and clonal
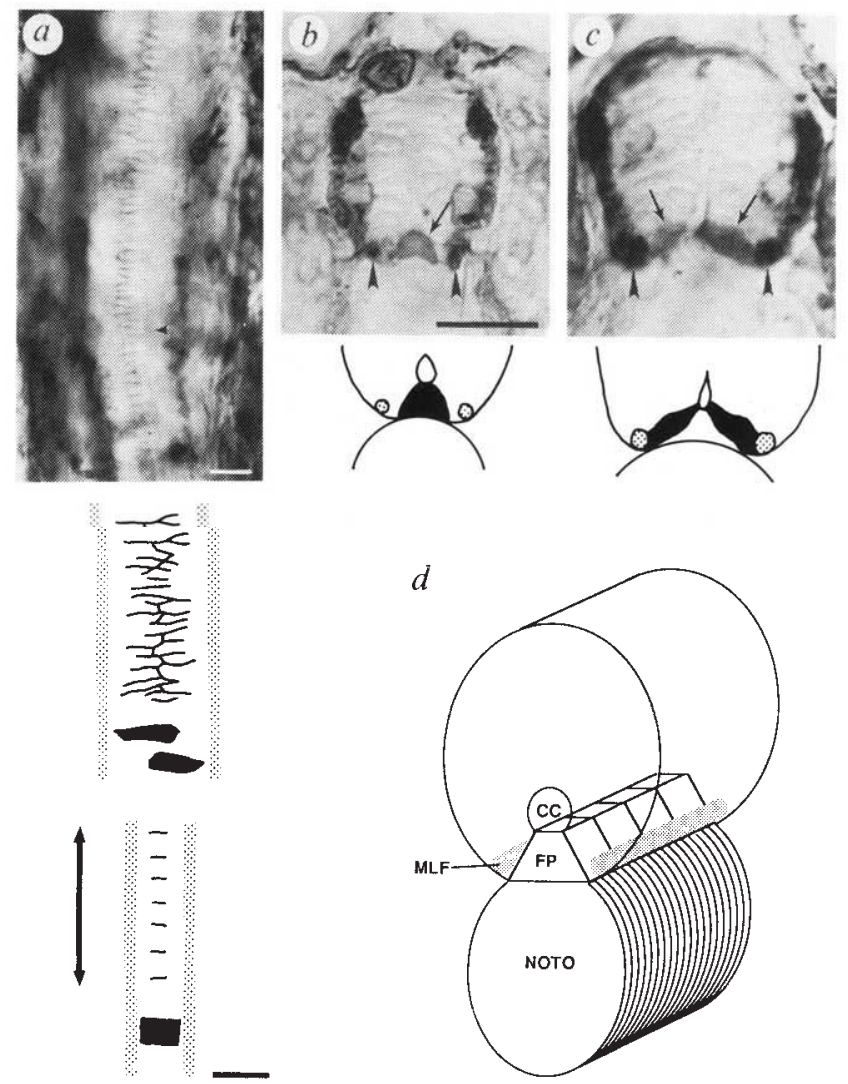

FIG. 1 The zebrafish embryonic FP is simply organized. a, The zn-5 monoclonal antibody labels the surfaces between adjacent FP cells. Dorsal view of the rostral spinal cord at $28 \mathrm{~h}$ postfertilization at $28.5^{\circ} \mathrm{C}$. Along most of the length of the spinal cord the FP is a single linear cell row (see ref. 4 for an alternative interpretation), and this structure changes at about the fourth spinal segment (arrowhead) to a staggered row, which continues into the hindbrain. The interpretive drawing shows this patterning in the spinal cord (lower) and hindbrain (upper). In both regions the ventral CNS fibre pathways termed the medial longitudinal fasicles (MLF; stippled) flank the FP. The double-headed arrow indicates one segment length. The number of FP cells per segment varies from about 25 in the hindbrain to 3 in the caudal spina cord. b, $c$, Transverse sections of spinal cord show that the MLF (arrowhead; as labelled with the monoclonal antibody $\mathrm{zn}-12^{23}$ ) is separated from the FP (arrow; as labelled by injection with lineage tracer in $b$ ), but contacts its neighbouring cells (arrows in $c$ ). $d$, Schematic representation of the topological relationships of the FP in the spinal cord. The FP underlies the central canal (CC), and is specifically juxtaposed to the underlying notochord (NOTO), also present as a single row of cells.

METHODS. Whole embryos were labelled by injection of a mixture of $5 \%$ rhodamine-dextran and $5 \%$ fixable biotin-dextran (Molecular Probes) into the yolk region of the embryo at the $2-8$ cell stages ${ }^{24}$. The tracers spread through the cytoplasm to all of the blasoderm cells. Later, 10-100 cells within or near the embryonic shield of the early gastrula were orthotopically transplanted to unlabelled hosts ${ }^{24}$. Hosts with labelled ventral CNS cells were selected by inspection of rhodamine fluoresence at $28 \mathrm{~h}$, and the biotin labelling was developed histochemically with streptoavidin/horseradish peroxidase (Vectastain) and diaminobenzidine, allowing detailed observation of the morphology of individual cells. The methods for immunohistology were as previously described ${ }^{23}$. After whole-mount staining, selected embryos were embedded in plastic and sectioned at $6 \mu \mathrm{m}$. Scale bars, $20 \mu \mathrm{m}$. 